\title{
Does it Matter How We Get There (Really)? A Case of Ethics in Bidding
}

\author{
Donald H. Schepers \\ Zicklin School of Business \\ Baruch College, City University of New York
}

Jim Snelling could not believe how tense he had become in the last 24 hours. A huge contract had become a huge headache. Just a week ago, Spectro had signed a $\$ 100$ million contract, and everyone was celebrating. Profits shot up, and Christmas bonuses doubled. Then came the news that Spectro's employees had the competitor's price list, and used it to undercut their bid. This morning, he was due at an Ethics Committee meeting to discuss what steps to take from this point forward. As senior strategist for the company, he was concerned not just with the company's sales and revenue for the three-year duration of the contract, but also the company's position as a supply chain partner for years to come. The decision today would have long-range consequences both inside and outside Spectro, and he weighed his position carefully.

\section{Spectro Electronics}

Founded in the mid-1960's, Spectro Electronics was a supply chain manager and distributor of electronic components to manufacturers. By 1995, Spectro was doing $\$ 6$ billion in sales, and the demand for its services kept growing. Jim was projecting that Spectro would be doing $\$ 10$ billion in sales within the next three years. Gross margins ran just over $16 \%$ of sales, and net income hovered right above $1 \%$ of sales, well within industry norms.

Spectro had a world-wide presence, serving manufacturers in over 40 countries. The company was organized into a series of regional operations staffs, with each staff handling sales, distribution, and engineering responsibilities for its area. The sales staff would solicit business from manufacturers in the form of quotes to fill. A manufacturer would be preparing to make some electronic component (a motherboard for a computer, for example) and would need a source for the parts for that component. Typically, these manufacturers would prefer to single-source their purchasing, and so would put all the necessary parts onto one quote. This quote would then go to supply channel managers such as Spectro and its competitors. The engineering staff at Spectro would assist sales in breaking down the quote into its various parts. The distribution staff would then solicit bids from its suppliers to fill the quote. Spectro alone had over 600 vendors it used to fill its parts orders. Competition among the supply channel companies was fierce, each trying to get the parts cheap enough and the final bid low enough to get some advantage over their rivals.

Typically, these bids would result in multi-year contracts. An average contract for Spectro ran over a 2 to 3 year period, and resulted in \$10-15 million in sales. Once a contract was awarded, the specifications passed to the regional distribution staff to service the contract. This staff provided just-in-time parts delivery and service to the 
manufacturer. At any one time, each regional distribution center was handling multiple existing contracts, as well as seeking new business.

There were 150 sales staffs across the 40 countries where Spectro had a presence, and 25 distribution facilities where parts would be housed and shipped. Each sales staff was headed by an operations officer who reported to the area's president. These area presidents were corporate officers. Spectro's service areas had been broken down into North America, Europe and the Mid East, South America, and Asia Pacific. In addition to these corporate presidents, other corporate officers included a CEO, CFO, CIO, a vice-president for Human Resources, and a vice-president for Global Strategy and Operations. Figure 1 shows the organizational chart for Spectro.

\section{Jim Snelling}

Jim Snelling had joined Spectro in 1992 as vice-president for Global Strategy and Operations. He had both a BBA and an MBA, and had specialized in operations. Before joining Spectro, he managed global operations for an automotive component company.

In his three-plus years at Spectro, the organization had grown tremendously, fueled in large part by the boom in technology services. As computers and other technology innovations dominated more and more in the workplace and home environments, supply chain management such as Spectro offered became an essential yet unseen part of the business environment. Each innovation spurred new demands and new contracts from manufacturers, and Spectro was working hard to make sure it had its piece of the pie.

One part of Spectro's growth strategy involved splitting regional sales staffs as that unit's business grew. Each sales staff worked hard to bring in as much new business as possible, and with the tech boom, Spectro had seen its share of growth. When a regional staff grew too large for one operations manager to handle, the corporate office stepped in, divided the territory into two, and named a new operations manager for the new territory.

Spectro used acquisitions as a second growth strategy. However, Spectro's competitors were growing faster than Spectro was, and as a result, the competitors grew faster than Spectro's ability to buy them. Try as it might, Spectro's management could see it was beginning to fall behind.

Growth brought new employees into Spectro, and the corporate office was very concerned with integration of employees into the culture of the firm. Within the first three months of their career at Spectro, new employees were brought to headquarters for a week of training. Training included introduction to the industry, as well as introduction to the company, its internal processes, and its culture, with the better part of one day devoted to ethics training. Employees from acquisitions were not brought in as 
quickly as others, however. Since they "knew the business" of electronic supply chain management, their training was put off until it was more convenient.

\section{The Opportunity and the Problem}

Jim had been concerned for some time about Spectro's strategies. While sales were good, they weren't as strong as he thought they should be, given what he could figure competitors were doing. There were a lot of repeat contracts, but nothing really new. The growth strategy was not working, and he debated what to do to get the company moving again.

In early 1996, Spectro's acquisition strategy got a boost from an unusual source. The United States Department of Commerce had entered an anti-trust ruling against ElectroSource, one of Spectro's main competitors. The ruling forced ElectroSource to divest some of its sales staffs, and Spectro acquired five of them in key regions where it had wanted to increase its presence. These staffs were merged into Spectro's existing staffs in those areas.

At first, the acquisition was rough. There were the usual frictions between long-standing and newly acquired employees over salaries, benefits, titles and the like. In addition, the cultures of the two companies didn't mesh all that well. For one thing, the industry was pretty rough and tumble. It was not uncommon for buyers to get a boat or some other 'goodie' from one of Spectro' competitors in return for a contract. ElectroSource operated close to the line, and everyone knew it. For its part, Spectro worked hard to run a clean operation. In addition, the ElectroSource employees saw the corporate structure at Spectro as having too much red tape. They perceived the electronics supply chain management business as rapidly moving, and they seemed to resent the oversight from Spectro's corporate offices.

Over the six months since the acquisition, however, Jim thought the resentment had waned, and the new employees were working out very well. They had brought new energy to the company, and he believed that would translate into new sales growth. Spectro needed a shot in the arm, and these employees seemed to have brought it.

In fact, one of these newly acquired staffs in the Southeast US had just signed a remarkable contract, $\$ 100$ million over 3 years. For Spectro, that was 6 to 10 times the normal contract size. That sale took Spectro's operating profit for the year from $\$ 40$ million to $\$ 56$ million. And they had taken the business away from their former employer! When Jim heard the news, he was glad these former ElectroSource employees were now working for Spectro, and not for ElectroSource. They had a real killer instinct, and Spectro needed more of that attitude.

It wasn't long after the good news that some disturbing signs began appearing. In reviewing the contract, the sales team manager noticed that the margins were a little thinner than usual, and almost dismissed it, thinking that it wasn't so out of line since the contract was so large. Looking at the team that won the bid, he also noticed that it was 
entirely composed of former ElectroSource employees. These employees had not yet been taken through the training system at corporate headquarters. He began to ask about the process of building the quote that won the bid. He was hoping that they had simply remembered enough to be very aggressive, but he knew that was a slim hope with over 20,000 parts in this one bid. One of the ElectroSource employees quickly confirmed his worst fears: they had brought original paperwork with prices and quantities listed. After all, these employees had reasoned, they had already worked up the price list once, and using it again wasn't illegal, so why not?

The sales team manager took the situation to the Regional Operations Manager, who also served on the Ethics team for Spectro. The Operations manager took this to the President for the North American region, who then brought it to the CEO.

When the CEO received the news yesterday, he quickly dictated a memo outlining the issue and circumstances of the bid, and called an emergency meeting of the Ethics Committee for the following morning to discuss the situation and develop an action plan.

The Ethics Committee consisted of the CEO, the Vice-President for Strategy (Jim), the Vice-President for Operations, the President of the business unit involved (in this case, the President of the North American division), and the regional Operations Manager for the particular unit. The team met on both an 'as needed' basis, and as well as a quarterly basis, with the quarterly review including reports from the heads of Human Resources, Information, and Finance. The Ethics Committee influenced behavior in the company both through its decisions related to specific incidents, as well as general ethics campaigns, with slogans such as "Do the right thing, even when no one is watching!"

Jim received the memo shortly after the CEO had dictated it. As he read the memo, his heart sank. Not only were the hopes for a revitalized strategy pushed aside, now there was all this to deal with.

Jim had spent the night puzzling over what he thought about the situation. Now he was in the office early, putting his thoughts together in preparation for the meeting later that morning. He would have to speak his mind on the contract, how to deal with the competitor, and what to say to the client. Sure, there was an obligation to the client, but was there any to the competitor? In his own mind, he had debated every position he could think of. Spectro could say nothing and let the contract run its course, hoping that nothing leaked to the competitor or client. That way, Spectro could profit from the contract, and somehow deal with the employees quietly on its own. At the other end, Spectro could admit the whole thing to both client and ElectroSource. Both would have demands on Spectro, and there was no way to know how much the competitor might want in order to be made whole. And at the very least, the client would want everything at Spectro's original prices.

There were also issues inside the company. How should the employees involved be dealt with? What happens to the bonuses that would have come from the contract? As 
he sat and looked out the window, he knew he had to make up his mind and take a position.

Figure 1. SPECTRO ELECTRONICS

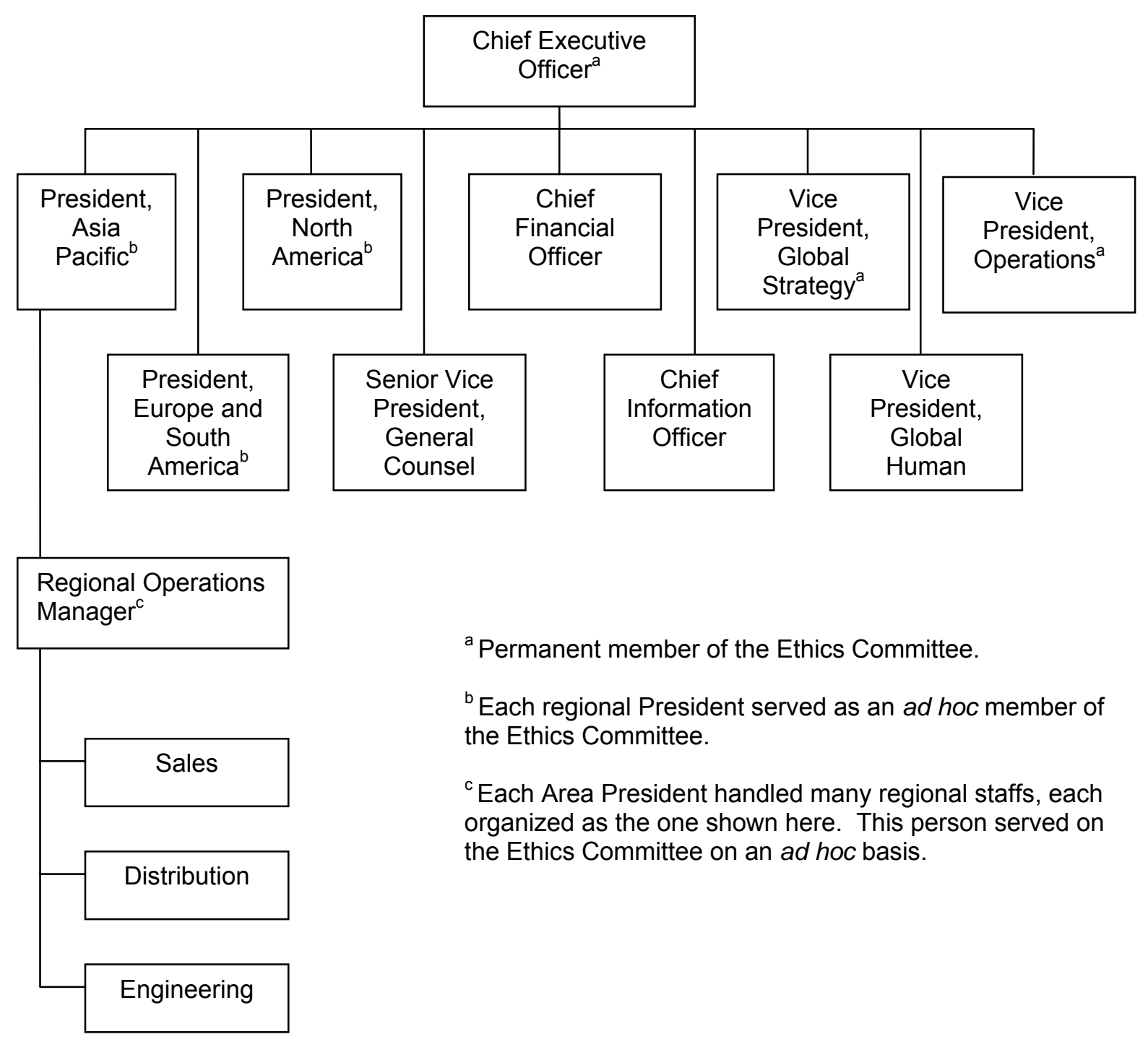

